\title{
Psicologia, Educação e Aprendizagem Escolar: avançando na contribuição da leitura cultural-histórica
}

\author{
Review Psychology, Education and School Learning: advancing \\ the contribution of cultural-historical reading
}

\section{Reseña Psicología, Educación y Aprendizaje Escolar: avanzando en la contribución de la lectura cultural-histórica}

\author{
Alexandra Ayach Anache \\ Universidade Federal de Mato Grosso do Sul - UFMS - Campo Grande - MS - Brasil
}

Martínez, A. M. \& Gonzáles Rey, F. (2017). Psicologia, Educação e Aprendizagem Escolar: avançando na contribuição da leitura cultural-histórica. São Paulo: Cortez Editora, 206p.

A obra em comento teve sua origem no convite feito pela Professora Ana Bock, organizadora da coleção "Construindo o Compromisso Social da Psicologia". Apresenta e aprofunda o conceito de aprendizagem escolar na perspectiva cultural-histórica resultante de um longo processo de construção da teoria da subjetividade, avançando por meio do aprofundamento da perspectiva teórica iniciada por autores da Psicologia russa.

O prefácio, elaborado por Bernardete Gatti, enfatiza o compromisso que essa perspectiva assume com a educação escolar, visando à construção de uma sociedade mais justa. Gatti ressalta a necessidade de um trabalho de transformação da realidade, que ofereça possibilidades de aprendizagens para o efetivo desenvolvimento dos indivíduos. Desse modo, a obra alcança docentes, psicólogos, gestores educacionais e outros que se interessem por investir no processo e aprendizagem escolar.

O livro está organizado em cinco capítulos, além das considerações finais. Ao longo de todo o texto, desde as partes pré-textuais, observa-se a densidade dos estudos sobre os conceitos relacionados à educação, bem como os subsí- dios orientadores para o trabalho pedagógico, conferindo à obra o caráter inovador.

O capítulo 1 apresenta os estudos sobre aprendizagem escolar na perspectiva cultural-histórica do desenvolvimento humano, a qual tem sua origem na Psicologia russa, influenciada pela filosofia marxista e pela ênfase que a cultura exerce na constituição do pensamento humano. Os autores salientam as contribuições de estudiosos que não são muito divulgados no Brasil, como Galperin, Davidov, Talizina e Menchiskaya; além disso, possibilitam novas leituras dos trabalhos de Vygotsky, considerando os vários momentos do desenvolvimento dos conceitos pertinentes à compreensão da aprendizagem escolar. As explanações mostram as contradições e os limites na concepção da psique que incialmente era considerada como sistema e não como conjunto de funções psicológicas superiores, conforme estava descrita na segunda fase da obra desse autor (1927 - 1931). Há referências ao livro Psicologia da Arte (1931 -1934), sobretudo no que tange à emocionalidade como caráter gerador da psique. Outros trabalhos referentes à psicologia da cegueira em Defectologia e compensação 
apresentam-se fundamentais para o desenvolvimento de conceitos que integram a teoria da subjetividade, dentre os quais o conceito de configuração subjetiva. Os autores do livro que aqui se resenha fazem alusão aos conceitos de situação social do desenvolvimento e também de perezhivanie, que consideram fundamentais para o reconhecimento do caráter singular do desenvolvimento e do rompimento da ideia de interiorização como refração do mundo externo.

Na segunda parte desse primeiro capítulo destacam-se as contribuições de Lídia Ilinitchna Bozhovich a fim de que se aprofundem os conceitos de motivos e personalidade que levam ao entendimento da psique como sistema, bem como se adense a concepção de aprendizagem escolar como processo subjetivo. Na última parte do capítulo são apresentadas as ideias de Boris Fedorovich Lomov como fundamentais no processo de revitalização da Psicologia soviética na década de 1979, com os estudos sobre a comunicação na aprendizagem escolar. Martínez Mitjáns \& Gonzáles Rey afirmam que as atividades não devem ser consideradas isoladamente, mas como sistema atividades-comunicação. Essa compreensão é fundamental para uma análise da complexa teia que envolve a situação de fracasso escolar de significativa parte dos estudantes de nossa sociedade.

O capítulo 2 aprofunda a dimensão subjetiva da aprendizagem escolar e apresenta as bases da teoria da subjetividade que vêm sendo desenvolvida por Gonzáles Rey desde 1997. Essa teoria aponta para a complexidade da constituição psíquica do ser humano considerando as condições da cultura e da vida social. Os quatro pilares do pensamento de Morin - paradigma da complexidade - contribuíram para adensar o corpus teórico sobre a subjetividade: subjetividade social, subjetividade individual, sujeito, configuração subjetiva e sentidos subjetivos. A subjetividade é definida por Gonzáles Rey (2003, p. 95) como

[...] formas complexas em que o psicológico se organiza e funciona nos indivíduos, cultural e historicamente constituídos, e nos espaços sociais das suas práticas e modos de vida. Por meio das experiências de vida, o sujeito se constitui como ser simbólico e emocional, conferindo ao psicológico o caráter multidimensional, recursivo, contraditório e imprevisível.

Portanto, a aprendizagem é um processo subjetivo no qual o individual e o sociorrelacional estão implicados. $\mathrm{Na}$ aprendizagem escolar, sentidos subjetivos são gerados, e é por meio deles que a história de vida de cada aprendiz integra-se ao contexto diferenciado vivido por eles nas salas de aula e na escola.

No capítulo 3 , intitulado $A$ subjetividade social e a aprendizagem escolar, os autores aprofundam o conceito de subjetividade social e como ela está implicada na aprendizagem escolar. Os autores criticam a versão mecanicista sobre a relação do social e da cultura na constituição do psiquismo humano, a qual foi predominante nas obras de Leontiev e também em alguns períodos das obras de Vygotski; apro- fundam o conceito de subjetividade social, apresentando-o como intimamente ligado à cultura e aos valores presentes na sociedade, os quais afetam as configurações da escola, uma vez que ela representa um sistema de configurações únicas em que se expressam os processos mais significativos da organização, os sistemas de relações e o trabalho de cada escola. Portanto, as práticas adotadas nesse ambiente impactam a qualidade da aprendizagem e do desenvolvimento dos estudantes e, desse modo, descontrói-se a perspectiva individualista de que o sucesso do aprendiz depende, unilateralmente, da relação professor aluno, da didática, da qualidade do docente e da capacidade dos estudantes, como é comum no processo de medicalização da vida. No entanto, Martínez e Gonzáles Rey não negam que em algumas situações há necessidade de se diagnosticar e medicar, conquanto isso não deva se constituir na justificativa para as dificuldades de aprendizagem ou mesmo de comportamentos que causam sofrimento.

É com esse cuidado que os autores abordam os temas das dificuldades de aprendizagem e das deficiências na perspectiva da inclusão, no quarto capítulo do livro. De forma original, os autores organizaram essa parte da obra apresentando as discussões sobre a Educação Inclusiva, alertando sobre os perigos e as contradições das políticas públicas e das produções científicas. Eles reconhecem que há necessidade de que mudanças substanciais aconteçam no âmbito da escola, sem que, no entanto, se perca de vista que o principal objetivo da educação formal é favorecer o processo de ensino e aprendizagem para todos, indistintamente. Nesse sentido, tal como sugerem, é necessário que se modifiquem as representações dominantes nas escolas como espaços de homogeneização, bem como acerca das impossibilidades de aprendizagem dos estudantes que apresentam deficiências e/ou aqueles que estão em situação de dificuldade de aprendizagem. Para isso, os autores sugerem que se avance em relação à construção de escolas inovadoras, ao investimento na formação docente tanto em nível técnico quanto em nível pessoal.

Nessa parte da obra, o capítulo 4, Martínez e Gonzáles Rey também oferecem sugestões referentes aos desafios presentes na subjetividade social da escola, dentre os quais a tendência de se enfatizarem as diferenças em detrimento da igualdade, o direito em detrimento dos deveres. Explicitam que para se superar a infantilização e superproteção de estudantes com necessidades educativas especiais é necessário reconhecê-los como sujeitos de deveres e prepará-los para o exercício da cidadania. Nesse sentido, os autores sugerem que se promovam mudanças referentes à subjetividade social da escola, como, por exemplo, em relação ao pessimismo disseminado pela cultura do déficit, o qual tem justificado as impossibilidades de aprendizado desses estudantes.

O capitulo 5 apresenta algumas implicações da dimensão subjetiva da aprendizagem para a ação do professor no que se refere ao trabalho pedagógico e à sua formação profissional, para a atuação das famílias e para a atuação e formação do psicólogo. Há sugestões valiosas 
de como contribuir para o sucesso da aprendizagem escolar em todos os níveis e, nesse sentido, os autores reafirmam a necessidade de que se invista no desenvolvimento de formas de aprendizagens compreensivas e criativas, as quais posicionam o estudante como sujeito que aprende. Eles defendem a adoção de um Sistema Didático Integral, definido por Mitjáns (1997) como um conjunto de princípios articulados de forma sistêmica, que orientam a atividade do professor e que contribuem para o desenvolvimento de recursos subjetivos, os quais podem favorecer os processos criativos da aprendizagem escolar.

Nas considerações finais os autores apresentam a síntese dos principais assuntos abordados nos cinco capítulos da obra, instigando o leitor a investir tanto na sua formação quanto na construção de práticas que favoreçam a transformação do indivíduo em sujeito de sua aprendiza- gem e ressaltam as contribuições da Teoria da Subjetividade na perspectiva cultural-histórica, tendo em vista que ela se constitui um campo aberto e incompleto assim como se caracteriza o conhecimento científico.

Os aspectos teóricos e metodológicos somados às sugestões para o trabalho pedagógico no âmbito das instituições escolares conferem originalidade à obra.

\section{Referências}

Gonzáles Rey, F. (2003). Sujeito e subjetividade. São Paulo: Thomson.

Mitjáns Martínez, A. (1997). Criatividade, personalidade e educação. Campinas: Papirus. 
